\title{
Analysis on Classroom Teaching Reform of Cultural Basic Course in Vocational School Based on Training of Vocational Core Competence in China
}

\author{
$\mathrm{Na} \mathrm{Hu}{ }^{1,2, *}$, Hua Xie ${ }^{1, *}$ \\ ${ }^{1}$ College of Education and Psychological Sciences, Sichuan University of Science \& Engineering, Zigong, P. R. C \\ ${ }^{2}$ Academic Affairs Office, Sichuan University of Science \& Engineering, Zigong, P. R. C \\ Email address: \\ 122362003@qq.com (Hua Xie), suse2017_hn@163.com (Na Hu) \\ ${ }^{*}$ Corresponding author
}

To cite this article:

$\mathrm{Na} \mathrm{Hu}$, Hua Xie. Analysis on Classroom Teaching Reform of Cultural Basic Course in Vocational School Based on Training of Vocational Core Competence in China. International Journal of Vocational Education and Training Research. Vol. 5, No. 1, 2019, pp. 23-28.

doi: 10.11648/j.ijvetr.20190501.14

Received: February 18, 2019; Accepted: March 20, 2019; Published: May 6, 2019

\begin{abstract}
The training of practical application skills is not only emphasized in vocational schools of our country, professional culture basic courses are set up to meet the urgent needs of society and enterprises for applied talents. Especially in the new era and new development situation, classroom teaching reform of cultural basis in vocational school based on training of vocational core competence attaches more importance to training the students' ability to transform and apply knowledge, so that they cannot only meet the needs of social development, but also meet the personal learning requirements to the greatest extent under the complete construction of classroom teaching system. At present, there are problems in the cultural basic courses of vocational schools, such as insufficient understanding of value of cultural basic courses, lagging reform of cultural basic courses; lack of close connection with specialized courses, controversy exists in the objectives and orientation of courses, and single teaching evaluation modes. Through the construction of course platform of vocational ability education, teaching display platform, activity development platform, practice entrepreneurship platform, and social platform five major platforms, the classroom teaching reform of the cultural basis in vocational schools can be effectively promoted.
\end{abstract}

Keywords: Vocational School, Cultural Basis Course, Professional Core Competence, Course Reform

\section{Introduction}

Vocational education occupies a very important position in education system of our country, it has a role that cannot be replaced by other educational forms, and it is also the main source of professional skill talents in our country. In recent years, with the continuous attention of the country, vocational schools are showing new vigor and vitality under the innovative development of vocational education, and also are on the threshold of new development opportunities. Vocational education includes the learning of language, mathematics, English, moral education and other cultural basic courses, and the cultural basic courses provide services for students' professional skill courses. However, many vocational schools ignore the value of cultural basic courses at present. In addition, modern vocational education pays more and more attention to the training of students' comprehensive quality, and the value of cultural basic courses lies in the fact that students' comprehensive quality can be comprehensively strengthened and the training objectives of professional core competence are consistent. The profession core competence has universal applicability in the personal ability and quality [1], and the courses which integrate professional core competence can effectively promote the improvement of students' humanistic quality education [2].

\section{The Importance of Training Students' Professional Core Competence in Vocational Schools}

At present, the society is in the rapid development and 
progress, competition is everywhere, and the competition of talents is particularly fierce, it promotes the training modes of talents in vocational schools not only to dominated by the training of professional core competence, but also the reform should be constantly optimized, and form a professional educational scale. The training of middle and senior professional skill talent not only must have the high skills to meet the needs of the times and society, but also have the basic cultural qualities. The training of professional core competence mainly focuses on the training of the qualities and abilities required by the profession needs.

As far as the training of professional core competence is concerned, having a good professional core competence can improve a person's cultural quality. On the contrary, good cultural quality also helps to develop a good professional core competence. At this stage, the deviation occurs in orientation of cultural basic courses in vocational schools; its important value is ignored, therefore, more and more educators are paying attention to how vocational schools implement reforms in the setting of cultural basic courses. Although the research on teaching reform of vocational schools at this stage has not been able to go deep, it still has great research value. In addition, the cultural basic course is an important basic for vocational school students to learn professional knowledge and reserve professional skills, which is also an important basis for training students' core competence, and it will also be related to students' future education and even career or job conversion [3].

At this stage, in allusion to vocational schools, whether professional core competence, or the reform of the cultural basic courses, there are not many studies. However, the research on the reform of the cultural basic courses based on the professional core competence is very lacking. Therefore, it is of certain educational practice to explore how to reform the teaching of cultural basic courses in vocational schools.

\section{The Definition of the Core Concept}

First of all, the so-called professional core competence mainly includes three components: basic core competence, expansion core competence and extension core competence. The basic core competence mainly emphasizes cooperation, exchange and communication between people; it must not only have a good sense of professional teamwork, but also can conduct self-management, as well as self-learning and improvement, the expansion core competence is mainly problem solving ability, and innovative and entrepreneurial ability, but also involves information processing ability; extension core competence mainly includes leadership and execution, and involves etiquette, personal management, team management, and psychological adjustment ability. Through the above-mentioned ability training, the comprehensive quality and ability that promotes its lifelong growth and development is formed [4].

Secondly, for vocational schools, the types of schools are divided into primary vocational schools and secondary vocational schools as well as higher vocational schools.
Among them, the primary vocational school is a vocational education based on the end of nine years of compulsory education. Secondary vocational schools enroll junior middle school and high school graduates, three years of teaching is generally adopted. Higher vocational schools enroll high school graduates and people with the same qualifications as high school; its basic school system is three years. At present, secondary and higher vocational education as the main, and the ratio of primary vocational education is gradually shrinking.

Thirdly, the vocational school course is broadly defined as the general name and the planning process for all subjects students should learn and all activities students should participate in for the purpose of education. In the narrow sense, it refers to a certain subject students should learn and the content of an activity that should be involved and the planning process. In vocational schools, the courses are mainly divided into two categories: cultural basic course and specialized course.

Finally, the cultural basic course is also called as public or cultural course, which refers to cultural theory course that students should study, and it mainly includes the learning of language, mathematics and other basic subjects.

\section{The Main Problems in the Cultural Basic Courses of Vocational Schools}

(1) There is misunderstanding in the value understanding of cultural basic courses

Most teachers generally believe that specialized courses in vocational schools are "major courses", while cultural basic courses drift into "minor courses", the result of students' cultural basic courses are relatively unimportant, so cultural basic courses are not dominant in vocational schools. The reason is, first of all, that the leadership has misunderstandings about the cultural basic courses. School leaders overemphasize whether schools can win prizes in skill competitions, or have advanced training bases, etc., and are confused by these glories to ignore the importance of cultural basic courses. Students originally have a weak basis and are not interested in the cultural basic courses, they can't get the joy of success in the learning, and teachers cannot achieve professional sense of achievement. Moreover, there is also a great unreasonableness in the performance-related pay distribution of teachers of cultural basic courses in vocational schools; this leads teachers to prefer to teach specialized courses rather than teach cultural basic courses. The lack of teachers of cultural basic courses has caused their sense of job burnout, which leads to the cultural basic courses can only struggle in the predicament and it is difficult to promote reform research [5].

(2) There is a lag in the reform of the cultural basic courses

Many vocational schools set thresholds in the course report, and the specialized courses of integrated teaching have great advantages. The specialized courses have won numerous awards in the major skill competitions, and a series of 
achievements brought about by the reform of specialized courses have formed good circles. In contrast, the cultural basic courses are in a stagnant state, and the reform is obviously lagging behind. The specialized courses have been transformed into modes combined theory with practice, when the construction of training places began, the cultural basic courses still remain in the theoretical teaching, and still focus on the teachers' blackboard-writing. Many vocational schools start promoting the school-enterprise cooperation model, and the work situation is introduced in the teaching, when the training bases inside and outside the school are continuously developed, the cultural basic courses still stay in the teaching mode based on classroom teaching. The cultural basic courses are far from the specialized courses in teaching form, [6].

(3) The cultural basic courses and specialized courses are not closely linked

At this stage, the cultural basic courses of many vocational schools still stay in the old-fashioned thinking in the setting of teaching objectives, blind following the unity of the content of the cultural basic courses, the cognition of knowledge system is too one-sided, and even some teachers think that cultural courses and specialized courses are irrelevant from subjective ideas. In addition, there is a certain difference among the disciplines, which makes the lack of internal connection between the cultural basic courses and the specialized courses, and even reluctant to connect with the specialized courses. Therefore, the cultural basic courses of vocational schools have always been excluded from the reform of professional talent training mode, which has caused the embarrassing situation, and it causes the teaching knowledge cannot adapt to the requirements of reform, not to mention the training requirements of professional talents, students' comprehensive professional ability cannot be improved. In the reform system of professional talents training in vocational schools, most schools' cultural basic courses lack the connection with specialized courses, therefore, the reform of cultural basic courses is greatly hindered, and the concept of cultural basic reform is also destined to be greatly affected.

(4) There is dispute in the objectives and orientation of the courses

In the reform process of the cultural basic courses, its course objectives and orientation has always been the most controversial part, especially in vocational schools. Vocational schools are places for training technical talents. Therefore, we always feel that the cultural basic courses are the basis for learning specialized courses. Although vocational schools must have school-running characteristics, their educational goals should be uniform, and they should have uniform requirements for the basic quality and cultural basis of students. All major vocational schools should integrate their own characteristics to carry out personalized education for students, and combine the favorable conditions of school-enterprise cooperation, re-plan and construct the course structure of the cultural basic courses, in order to achieve the objectives of the courses, and correctly position the courses; this is an urgent problem to be solved at this stage, moreover, and it is also an obstacle which urgently need to be removed in the reform path of the cultural basic courses.

(5) Single teaching evaluation mode

Limited by the professional attributes of vocational education, the leaders, teachers and students of the vocational school put most of their time and energy into the specialized courses. Moreover, a professional evaluation mechanism for tripartite certification is also created, which has become one of the most effective and authoritative ways to identify students' professional skills and teaching evaluation of each major. Students can obtain the corresponding certificate through evaluation and certification, as the basis for the evaluation of students' results, and it is recognized by the school, teachers and students. However, there is no such professional certification in the cultural basic courses, and the evaluation mechanism set by the school is not reasonable or not comprehensive, the test paper has become the only evaluation mode, the students will be divided into "poor students" and "top student" according to this, which seriously hurt students' self-confidence and enthusiasm, the learning evaluation loses its effect. Moreover, students can't form a good attitude towards learning, it does not motivate students, so teachers and students pay less attention to the cultural basic courses [7].

\section{Building Five Major Platforms to Promote Classroom Teaching Reform of Cultural Basic Courses}

(1) Course platform of professional ability education

1. Professional basic literacy course

The professional basic quality course refers to the humanistic quality course; this course includes the following courses, namely, public courses and mental health education courses, as well as career development and entrepreneurial education courses, in addition, some basic courses, some basic courses are also included, these belong to scope of compulsory courses, the aims are to provide students with a solid knowledge base to promote their comprehensive development.

2. Professional general ability course

The professional general ability course refers to a series of specialized courses which professional ability teaching infiltrate into, and effectively implements into the course syllabus, and fully reflects in the teaching process of specialized courses, thus training students through the learning of professional general ability courses, train students' professional quality and the effective mastery of knowledge and skills.

3. Professional core ability course

The pioneer of modern vocational education in our country, Huang Yanpei said that "vocational education should be a combination of theory and practice, and parallel knowledge and skills." In order to effectively build students' professional core ability, it must be achieved through professional core course education, but also have specific professional activities, or introduce simulated career situations in the course education process, their own professional knowledge 
and skills are combined, as well as professional attitudes and other analogical transfer, promote the good construction of their professional core ability.

4. Professional expansion ability course

The professional expansion ability course mainly includes three parts: the first is the professional limited optional course; the second is the public compulsory course, and the third is comprehensive quality training. The course design of the above three parts is mainly to train students' independent learning ability, and then can work independently, moreover, students must have good interpersonal communication skills, therefore, the course also includes the setting of individual psychological endurance course [8].

(2) Teaching display platform

The teaching of specialized courses in vocational school education is a particularly important means of education, and it is also the main way to train professional talents, the comprehensive vocational ability training of students as the focus and scientifically work out course arrangement, while paying attention to the teaching of professional core courses, integration with professional basic courses is also emphasized, a scientific course system is established, make it form an innovative teaching mode of school-enterprise cooperation on the basis of professional applicability, and carry out teaching work aiming at professional applied talents training, the course setting should be committed to training practical talents who adapt to technology and serve technology; the needs of the market economy is integrated and considering the personnel need of enterprises and public institutions, the course setting should fully reflect the current new technologies and services, as well as new techniques and methods, fully implement the spirit of " studies on the theoretical and practical issues of party building", carry out innovation in the course, actively train students' creative ability and improve students' social competitiveness, on this basis, we must also strive to train students' adaptability to changes and make them better serve the society.

It is necessary to have a good professional ethics and deeply understand professional norms in specialized course education. Higher vocational schools should realize integration of teaching, learning and doing in the course education of students' professional ability training, which have lots of benefits for students to form a complete knowledge system in their minds, and it is also conducive for students to carry out more practical experiences. By building a simulation training room that integrates teaching, learning and doing, it can not only simulate the workplace environment, but also create good practical opportunities for students, it makes students to enter the enterprise more and understand the enterprise, moreover the students can quickly adapt to the job needs after entering the workplace, they can also combine their own specialized courses and show their talents in good knowledge transformation, and can further understand and know the enterprise idea, make students use their professional knowledge in daily life, and integrated existing humanistic literacy concept, fully display their professional platform and life platform [9].

\section{(3) Launching activity platform}

There are many activity contents related to the construction of campus culture, including student class activities and community activities, as well as student union' activities and school routine activities and so on. Students participate in various types of campus cultural activities to enhance their comprehensive professional ability. In the building process of campus culture, it is necessary to pay attention to the cultural integration between schools and enterprises, realize the comprehensive sharing of knowledge and information, and further promote organic integration between enterprise culture and higher vocational education by organizing some activities related to career planning competitions. In order to fully train and improve students' ability to connect with enterprises in the future employment process, the school must strictly require students, students must have a certain basic understanding for the enterprise and society, and on this basis, schools guide students to establish a strong career ideals and beliefs, make students to successfully enter the workplace from the campus and enter into social life.

For example, students in higher vocational schools may try to implement an enterprise-style management system in the class management work during the campus entrepreneurial exercise, and follow the management model of the enterprise, on the corridor walls of various places such as the administrative building, the teaching building and the training ground, post the classic quotations of famous entrepreneurs or some advanced management concepts at home and abroad, etc., on this account promote the current advanced enterprise management model and concept, moreover, also highlight the normative industry standards, and vigorously propagate special professional contents of the world's leading energy conservation and environmental protection and so on. Holding enterprise culture competitions and professional skills design competitions are emphasized, as well as works display activities, etc., making students in higher vocational schools seem to be in a professional environment, thus strengthening their professional ethics. By strengthening the construction of campus cultural activities, students can improve their adaptability, learn how to control their emotions, moreover, their teamwork and social skills can be enhanced, thus improving their professional ability platform.

(4) Practice entrepreneurship platform

The students' vocational skills of the higher vocational schools can be effectively improved and expanded through the entrepreneurial education activities, the professional knowledge of the students is more solid and fully expanded, and on this basis, the students' entrepreneurial skills are fully demonstrated, and make students get the synchronous promotion of innovative spirit and creative ability. Especially when vocational schools launching construction of entrepreneurial education course system, it is necessary to attach importance to the training of students' entrepreneurial knowledge and basic entrepreneurial skills. It is necessary to make students have basic economic knowledge, moreover, have a basic understanding and mastery of the industrial basic economics common sense and related policies, on this basis, it 
is also possible to infiltrate media propaganda and marketing ways in course design. In addition, students must have a certain understanding and mastery for entrepreneurial knowledge of investment project feasibility studies and so on.

In addition to the above contents, the students must also understand some basic enterprise management knowledge; have a certain grasp for enterprise report, enterprise management and enterprise operation. Based on this, in the entrepreneurial education link of higher vocational schools, it is especially pay more attention to the training of students' emotional quotient. Through the learning of relevant courses, actively training students' healthy and stable mentality, and shape students' sound personality, so that students can learn how to establish and maintain good interpersonal relationships, and know how to manage their own interpersonal relationship network, thereby improving students' entrepreneurial benefits [10].

(5) Integrate social platform

There are many types of social practice activities, among which we are familiar with visits and part-time-work and part-time-study, and can also conduct social research activities. Through social survey and part-time-work and part-time-study and so on, under the premise that continuously promoting students to enhance social practice, the students can not only personally walk into the enterprise to conduct practice, but also effectively participate in some relevant social training, on this account the students achieve the training of students' self-motivation and self-discipline, moreover, it also achieve the goal of training students' self-education ability, and then students can better adapt to social needs after enter into the society, and further enhance their social viability. The most advantage is to exercise the character of the students through social practice activities, fully stimulate students' exploration desire, and make students build awareness of self-respect and fair competition.

In addition, social practice is used to teach students to empathize, how to respect others, train students' collaboration ability, establish good interpersonal relationship and improve students' moral character. In addition, according to the production process of the enterprise, the real production environment of the enterprise is restored to realize the liberation of students' hand. Taking the management mode of the enterprise as a reference, in the learning process of the student's course, let the students personally experience the working atmosphere of the enterprise, and carry out the course education in strict accordance with the enterprise norms, the attendance management mode of the enterprise can be introduced into the course education, and the punching card system can be implemented, thus effectively training students' rigorous professional attitudes. Enterprise idea is posted within students' sight, thus urging students to be strict with them. Students can experience the enterprise atmosphere in this stressful and normative environment, which is completely different from the leisurely and relaxed atmosphere of campus life, and are no longer self-centered.

\section{Conclusion}

In the process of training talents, vocational schools must not only establish innovative teaching concepts, but also pay attention to adhere to "putting people first" basic principle and fully improve students' comprehensive quality ability, so that the in-depth promotion of vocational education reform can be achieved finally. Through continuous summary of vocational education practice, fundamental innovation is implemented in classroom teaching; structural optimization of the basic course and the application of diverse teaching methods all can make effective adjustments, thus forming a new pattern centered on training students' professional core competence.

\section{Acknowledgements}

This paper is based on a research project financially supported by the Research Center for Aesthetics and Aesthetic Education "Research on the Current Situation of Implementation and Optimization Path of Aesthetic Education in Vocational Schools in Sichuan Province" (18Y029) and financially supported by the Southwest Music Research Center "Research on Talent Cultivation Model of Integration of Enterprises with Colleges and Universities of Music Education Major in Higher Vocational Schools in Sichuan Province" (xnyy2018021).

\section{References}

[1] Tong Ge. How is the Professional Core Competence "Trained"-Take Liuzhou City Vocational College as an Example [J]. China Employment, 2018 (06): 52-53.

[2] Zhang Jing. Vocational Core Competence Course Help the Development of Humanistic Quality of Higher Vocational Students [J]. The Guide of Science \& Education, 2018 (11): 22-23.

[3] Liao Junjie, Zhou Xiaoping, Li Guifeng, et al. Reform and Practice of Embedded Teaching Model of Professional Core Competence $[\mathrm{J}]$. Chinese Vocational and Technical Education, 2016 (8): 54-57.

[4] Wu Liping, Xie Renmei, Xi Guangqing. Preliminary Study on the Reform of Basic Courses in Higher Vocational Education from the Training of Professional Core Competence [J]. Adult Education, 2012, 32 (8): 41-42.

[5] Leng Xuefeng, Ren Aizhen, Jiang Zhengyan. Exploration on the Integration of Theory and Practice of Higher Vocational Courses Based on the Training of Professional Core Competence $[\mathrm{J}]$. Chinese Vocational and Technical Education, 2016 (14): 18-23.

[6] Liu Jinfeng. Implementation and Thinking of the Teaching of Professional Core Competence Course in Higher Vocational Schools [J]. Education and Vocation, 2014 (17): 133-134.

[7] Ding Hui. Thinking on the Teaching Reform of Professional Core Competence in Higher Vocational Schools [J]. Education and Vocation, 2013 (2): 176-177. 
[8] Wu Yaqin. Exploration on the Teaching Reform of Business English in Higher Vocational Schools from the Training of Professional Core Competence [J]. Journal of Harbin Institute of Vocational Technology, 2013 (3): 37-38.

[9] Liang Xiangping. Teaching Reform of Higher Vocational Tourism Majors Based on Professional Core Competence [J]. Journal of Nanchang College of Education, 2016, 31 (4): $85-88$
[10] Cao Yang, Feng Qilin. Study on Project Curriculum Design and Implementation Based on the Cultivation of Vocational Core Abilities of Higher Vocational Students [J]. Vocational and Technical Education, 2014, 35 (7): 37-41. 